\title{
Adverse Event End Relative to Reference Time Point
}

National Cancer Institute

\section{Source}

National Cancer Institute. Adverse Event End Relative to Reference Time Point. NCI

Thesaurus. Code C87838.

An indicator of the conclusion of the adverse event in relation to a specific point in time. 